\title{
Urinary lodine levels determined by inductive Couple Plazma Mass Spectrometry in the State of Kuwait
}

\author{
Amina Ali \\ Kuwait Institute for Scientific Research, P.O. Box 24885, Safat13109, Kuwait;Fax:0096524989059;E- \\ mail:aahmed@kisr.edu.kw
}

Accepted 21 December, 2016

lodine is an essential element which is utilized by the thyroid gland for the biosynthesis of the thyroid hormones. These hormones strongly influence an extended range of biochemical reactions. Immune defense and antibody production depend on reliable thyroid function. lodine is obtained only through the diet and is mainly absorbed by the gastrointestinal tract as the inorganic anion, iodide. The status of iodine nutrition of a population is determined by measurements of iodine as urinary iodide (UI) concentration since it is considered an indicator of the adequacy of the iodine intake of that population. In general, it is assumed that most ingested iodine, such as sodium or potassium iodide, is excreted in the urine, and that equilibrium is established between dietary iodine intake and $\mathrm{UI}$ excretion. Inductively coupled plasma mass spectrometry provided reliable results for $\mathrm{UI}$ determination, collected from a Kuwaiti population. Results were found in accordance with World Health Organization (WHO) criteria( greater than $100 \mu \mathrm{g} / \mathrm{L}$ ) and not more than $7 \%$ of the population with $\mathrm{UI}<50 \mu_{\mathrm{g}} / \mathrm{L}$. Only one severe deficiency case was observed with $\mathrm{UI}<10 \mu_{\mathrm{g}} / \mathrm{L}$.

Keywords: Thyroid; Hormones; Immune; Antibody; Diet

\section{Introduction}

lodine is an essential component of the thyroid hormones that play an important role in human development, growth, and metabolism. lodine deficiency disorders (IDDs), the effects of iodine deficiency, are still a major problem in public health in many parts of the world. According to the World Health Organization, the epidemiological criteria for IDD are as follows (median values): severe, $<20 \mu \mathrm{g} / \mathrm{L}(0.16 \mu \mathrm{mol} / \mathrm{L})$; moderate, 20 $49 \mu \mathrm{g} / \mathrm{L}(0.16-0.38 \mu \mathrm{mol} / \mathrm{L}) ;$ mild, 50-99 $\mu \mathrm{g} / \mathrm{L}(0.39-0.78$ $\mu \mathrm{mol} / \mathrm{L})$; and no deficiency, $>100 \mu \mathrm{g} / \mathrm{L}(0.79 \mu \mathrm{mol} / \mathrm{L})$. Urinary iodine ( $\mathrm{UI})$ concentrations directly reflect dietary iodine intake and consequently test biochemical assessment of the iodine status worldwide. Switzerland was one of the pioneering countries in the prevention of IDDs by iodizing table salt. In 1922, iodized salt became commercially available for human consumption in that country.

Inductively coupled plasma mass spectrometry (ICPMS) has become a popular method for the reliable determination of trace elements in samples of biological and environmental origin. The appearance of commercial ICP-MS instruments offered the clinical laboratory fast, multielement determinations, reduced sample consumption, simplified sample preparation and access to a wider range of analytes at trace levels. Deposit these promises, limitations due to the sample matrix were encountered. Typically, with ICP-MS, an upper total dissolved solids (TDS) limit of $0.2 \%$ in the solution should not be exceeded to ensure continuous operation for an extended period. At TDS levels in excess of this limit, cone orifice blockage, plasma injector clogging and unacceptable levels of signal instability are commonly experienced. Thus, most clinical samples need to be diluted by a factor of $10-20$ to overcome this limitation. At levels below $0.2 \%$ TDS good performance is expected. However, interferences due to the sample matrix may still be present. Interferences in ICP-MS fall into two categories-spectroscopic and non-spectroscopic: Non- 
Table 1. ICP-MS operating conditions

\begin{tabular}{|c|c|}
\hline Plasma & \\
\hline Radiofrequency power & $1.1 \mathrm{~kW}$ \\
\hline Auxiliary gas flow rate & $0.80 \mathrm{~L} / \mathrm{min}$ \\
\hline Cooling gas flow rate & $15.0 \mathrm{~L} / \mathrm{min}$ \\
\hline Nebulizer gas flow rate & $0.75 \mathrm{~L} / \mathrm{min}$ \\
\hline \multicolumn{2}{|l|}{ Vacuum conditions } \\
\hline Expansion chamber interface & $0.4 \mathrm{kPa}$ \\
\hline Quadrupole mass spectrometer & $0.002 \mathrm{kPa}$ \\
\hline \multicolumn{2}{|l|}{ Data acquisition } \\
\hline Monitored ions $(\mathrm{m} / \mathrm{z})$ & ${ }^{12 /} I,{ }^{129} \mathrm{I},{ }^{131} \mathrm{Xe}$ \\
\hline Read delay & $90 \mathrm{~s}$ \\
\hline Mode, normal resolution & Peak jump \\
\hline Dwell time per peak (one point) & $50 \mathrm{~ms}$ \\
\hline Sweeps & 20 \\
\hline Replicate sweeps & 20 \\
\hline Wash-out time & $150 \mathrm{~s}$ \\
\hline $\begin{array}{l}\text { The advantages of ICP-MS } \\
\text { include: } \\
\text { Greater sensitivity and detection I } \\
\text { methods } \\
\text { Direct analysis of some types of liq } \\
\text { Low spectral interference }\end{array}$ & $\begin{array}{l}\text { spectrometry } \\
\text { limits than other } \\
\text { quid samples }\end{array}$ \\
\hline
\end{tabular}

spectroscopic interferences are indicated by a general suppression or enhancement of signals and are commonly handled by a combination of dilution and internal standards.

Spectroscopic interferences, or isobaric overlaps, are usually a results of the formation of polyatomic ions , typically between the plasma gases (e.g. Ar, O, N, H, C) and the major elements of the sample matrix (e.g. $\mathrm{Na}$, $\mathrm{Ca}, \mathrm{Mg}, \mathrm{C}, \mathrm{Cl}, \mathrm{S}, \mathrm{P}$ for clinically samples). These polyatomic species cause deterioration of detection limits by increasing the background signal at the mass of interest.

\section{EXPERIMENTAL}

\section{Instrumentation}

A Perkin-Elmer Sciex Elan 6100 ICP-MS (See figure 1) equipped with the Perkin-Elmer AS90 auto sampler and a parallel path high solids nebulizer obtained from Technical Solutions were used. Because the efficiency of a pneumatic nebulizer is $<10 \%$, the major portion of the iodine was collected and pumped into a waste container. To avoid clogging the nebulizer orifice, which may lead to an erratic loss of signal intensity, the samples were centrifuged for $12 \mathrm{~min}$ at $5000 \mathrm{rpm}$. Additional details of the instrument and operating conditions are summarized in Table 1.

\section{Calibration}

Continued calibration of the instrument is a component of the overall quality control plan and should be performed by analyzing one mid-concentration standard after every 10 analyses. The relative percent difference (RPD) between the initial calibration and the continuing calibration should be less than 15 percent.

\section{Sample Preparation}

\section{Reagents}

Analytical grade ammonia (35\%) solution was obtained from Merck. Potassium iodated $\left(\mathrm{KIO}_{3}\right)$ were obtained from Merck. Argon with a purity grade of $99.998 \%$ was supplied by Carbagas 
Table 2 . Intensity reading of I calibration standards for range $0.0-50 \mu \mathrm{g} /$

\begin{tabular}{lc}
\hline conc. & Intensity \\
\hline 0 & 2810 \\
5 & 29565 \\
10 & 55038 \\
50 & 270712 \\
\hline
\end{tabular}

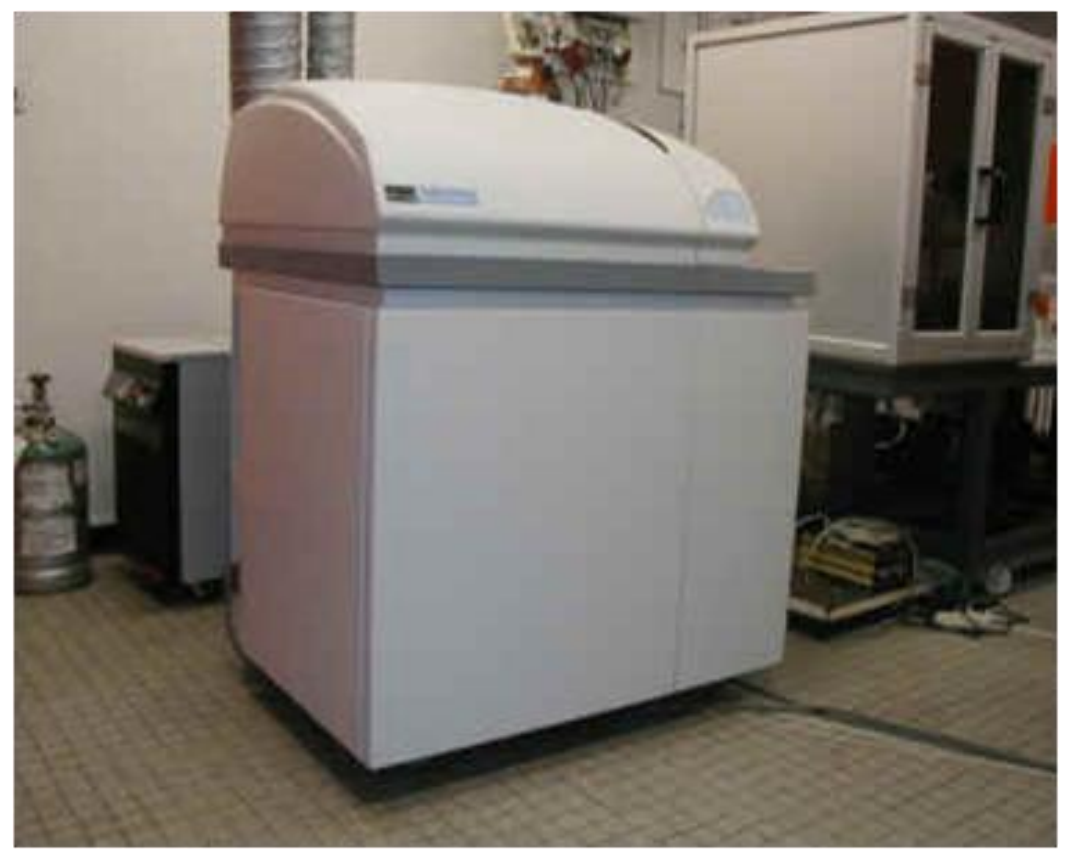

Figure 1. A Perkin-Elmer Sciex Elan 6100 ICP-MS.

\section{Standards}

The calibration solution was the standard diluents with aliquots added of the working stock standard $(1000 \mathrm{mg} / \mathrm{L}$ prepared from $0.13 \mathrm{~g} / 100 \mathrm{ml} \mathrm{KIO)} \mathrm{in} \mathrm{ultra} \mathrm{pure} \mathrm{water} \mathrm{to}$ yield final concentrations of $0,5,10$, and $50 \mu \mathrm{g} / \mathrm{L}$. A reagent blank and an I solution were measured at intervals of every 10th sample to detect any variation during the measurement period.

The results obtained should fall within the published range of acceptance values. When no control limits are provided, a range of 50 to 150 percent should be used. The urine samples came from (300) healthy and sick people. The samples were stored in polystyrene tubes. The analysis of samples stored for several weeks at $20 \mathrm{C}^{\circ}$ did not show any variation in iodine concentration with respect to those analyzed earlier.

The sample solutions consisted of $0.5 \mathrm{ml}$ of the $0.1 \%$ ammonia $(35 \%)$ solution and $1 \mathrm{ml}$ of urine that were diluted to $10 \mathrm{ml}$.

\section{Results and Discussion}

lodine Calibration curve was measured prior to measurement of urinary iodine samples. The intensity readings of iodine Calibration Standards for Calibration Range $0.0-15.0 \mu \mathrm{g} / \mathrm{L}$ are shown in table 2 and figure 2 . Table. 3 shows part of the three hundred sample has been taken to sick and healthy people. Accuracy Preliminary validations were made by measuring various iodide solutions of known concentrations. Recovery that was investigated by adding a known amount of iodine concentration $(10 \mu \mathrm{g} / \mathrm{L})$ to the selected sample was $91.2 \%$ is shown in table (4). So far, no urine control material that is certified for iodine has been available commercially. The repeatability, here defined as the ability of a method to give the same answer when repeated several times in a single day by a single analyst, was estimated and is summarized in table(5). 


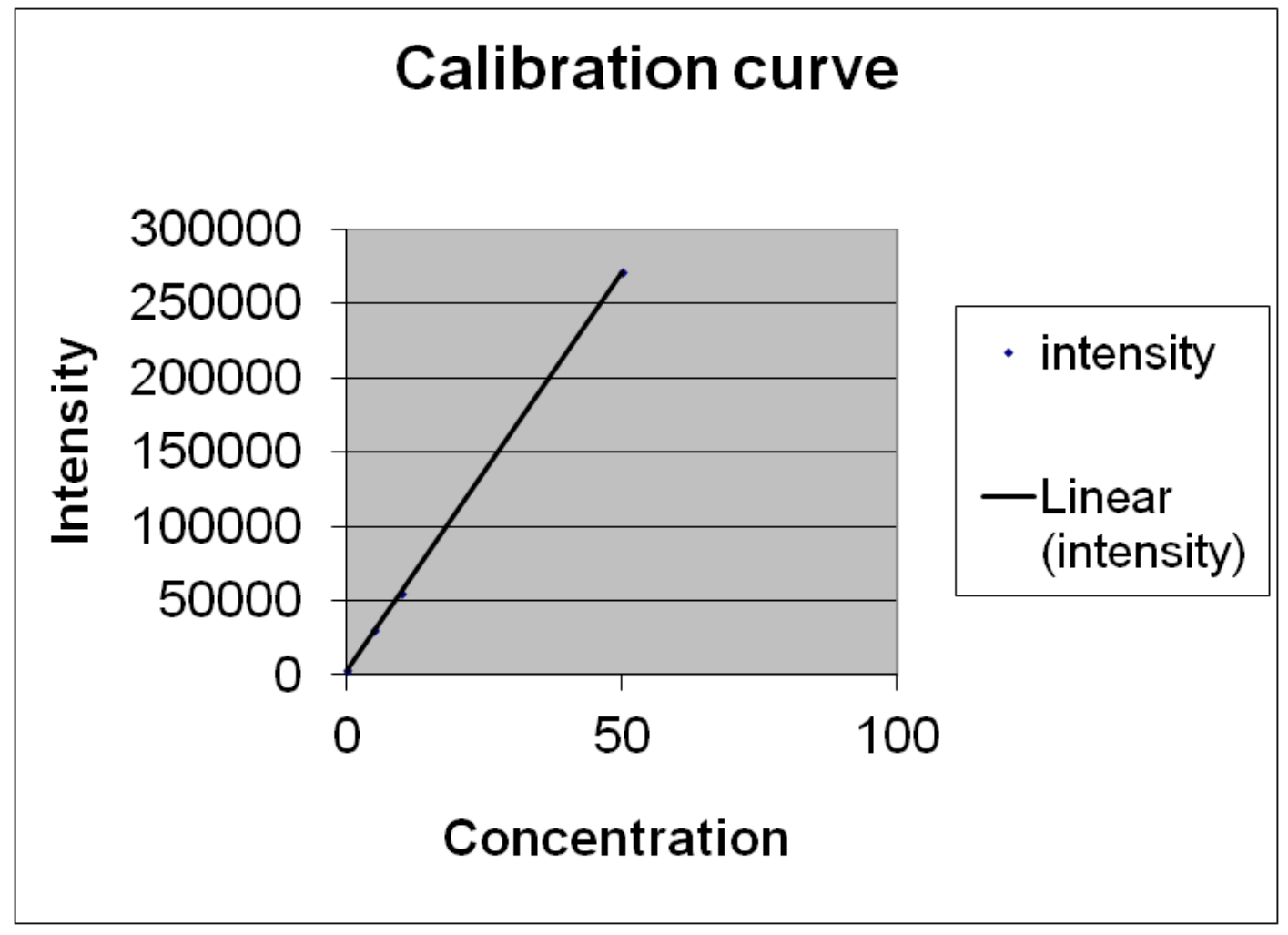

Figure 2. I calibration standards for range $0.0-50 \mu \mathrm{g} / \mathrm{l}$

Table 3. lodine Concentration for part of (300) People

\begin{tabular}{lccccc}
\hline Sample no & lodine & Sample no & lodine & Sample no & lodine \\
\hline 1 & 379 & 13 & 717 & 25 & 56 \\
2 & 308 & 14 & 590 & 26 & 61 \\
3 & 365 & 15 & 485 & 27 & 32 \\
4 & 277 & 16 & 865 & 28 & 51 \\
5 & 407 & 17 & 444 & 29 & 53 \\
6 & 379 & 18 & 258 & 30 & 35 \\
7 & 373 & 19 & 338 & 31 & 69 \\
8 & 493 & 20 & 838 & 32 & 54 \\
9 & 1705 & 21 & 112 & 33 & 74 \\
10 & 454 & 22 & 234 & 34 & 83 \\
11 & 348 & 23 & 102 & 35 & 34 \\
12 & 799 & 24 & 173 & 36 & 20 \\
\hline
\end{tabular}

Table4. Recovery of lodine Spiked Urinal Sample

\begin{tabular}{lccc}
\hline Sample 12 & lodine Calculated $(\boldsymbol{\mu g})$ & lodine Measured $(\boldsymbol{\mu g})$ & Recovery \\
\hline diluted 10 times & - & 79.9 & - \\
diluted 10 times $+10 \mathrm{ppb}$ I & 89.9 & 87.6 & $91.2 \%$ \\
\hline
\end{tabular}


Table 5. lodine Concentration results For Selected Samples And Their RSD.

\begin{tabular}{lcccccc}
\hline Sample No. & Run $\mathbf{a}$ & Run $\mathbf{b}$ & Run $\mathbf{c}$ & Run d & Run e & RSD \\
\hline 21 & 112 & 115 & 117 & 115 & 121 & 2.86 \\
22 & 234 & 240 & 238 & 244 & 246 & 1.98 \\
23 & 102 & 99 & 103 & 103 & 102 & 1.61 \\
24 & 173 & 165 & 172 & 176 & 178 & 2.88 \\
\hline
\end{tabular}

\section{Conclusions}

The results of this study show that the proposed ICP-MS method provides a direct and accurate determination of iodine in human urine with sufficient precision over a wide range of concentrations.

\section{Reference}

Centers for Disease Control and Prevention, Division of Laboratory Science. lodine in urine, DLS method code: 2001/04-OD. Revised August 22, 2001CLIA methods 2001:1-20 Centers for Disease Control and Prevention Atlanta, GA.

National Center for Health Statistics. Iodine level, United States, 2000. (Accessed October 31, 2002).
UNICEF. The state of the world's children 1998 1998:53-58 Oxford University Press New York.

WHO. Indicators for assessing iodine deficiency disorders and their control through salt iodization. Document NUT/94.6 1992:22-24 WHO Geneva. 